\title{
Richter's Hernia After Gynecological Laparoscopic Procedure: A Case Report
}

\author{
Emre E. TAŞ ${ }^{1}$, Gülin F. YEĞin AKÇAY' ${ }^{2}$ Ayşe F. YAVUZ ${ }^{1}$
}

\footnotetext{
${ }^{1}$ Department of Gynecology and Obstetrics, School of Medicine, Yıldırım Beyazıt University, Ankara, Turkey.

${ }^{2}$ Department of Gynecology and Obstetrics, Ataturk Education and Research Hospital, Ankara, Turkey.
}

\section{ABSTRACT}

Richter's hernia is defined as a type of hernia in which only part of the circumference of the antimesenteric border of a bowel wall is incarcerated within the hernia sac. This is discrete from other types of abdominal hernias in that only one intestinal wall protrudes through the defect, such that the lumen of the intestine is incompletely contained in the defect, while the rest remains in the peritoneal cavity. Due to the fact that, clinical presentation of Richter's hernias is variable and it may be hard to diagnose immediately and high suspicion is also required for correct diagnose and promptly remediation. In this report, we present a case of Richter's hernia after gynecological laparoscopic procedure occurring in a 62 year-old female, in order to warn surgeons and avoid similar complications.

Keywords: Hernia, Laparoscopy, Richter

\section{INTRODUCTION}

In gynecology; the modern laparoscopy, which is used for a multitude of gynecologic and nongynecologic indications, was first used in the 1980s to diagnose and treat infertile couples (1). However, with the use of high-resolution and highdefinition video cameras, complex gynecological procedures, which were previously performed by only laparotomy, can be performed via laparoscopy. Operative laparoscopy has the benefit of shorter hospital stays, less postoperative pain, and faster return to normal activity (2). Therefore, adnexal procedures, such as ectopic pregnancy and ovarian cystectomy; uterine surgery, such as myomectomy and hysterectomy; reconstruction of the pelvic floor, such as retropubic urethropexy and sacral colposuspension; and finally the staging and treatment of gynecologic cancers are performed widely and with great success by surgeons presently (1).

Although laparoscopy has many advantages compared with laparotomy, it has many specific complications. These complications have been associated with visualization in conjunction with the change in anatomic perspective that may increase the risk of damage to blood vessels or vital structures such as the bowel, ureter, or bladder.

This study aimed to present a rare complication of laparoscopic procedure, Richter's hernia, to warn surgeons and avoid similar complications.

\section{CASE REPORT}

A 62-year-old woman, multiparous and at menopause for more than 10 years, was admitted to the clinic with a solid and unilateral adnexal mass with more than $5 \mathrm{~cm}$ diameter. She had no history of surgery or systemic diseases. Serum tumor markers studied before surgery, such as cancer antigens (CA 125, CA 19-9, CA 15-3, carcinoembryonic antigens), were within the normal range, and the malignancy risk index was 60 points. Laparoscopy was performed after discussing with the patient about the surgical approach and obtaining written consent form. A solid, unilateral left ovarian mass

Correspondence:

Gülin F. YEĞiN AKÇAY

Atatürk Eğitim ve Araşttrma Hastanesi, Jinekoloji ve Obstetrik Bölümü, Eskişehir Yolu-Bilkent Cad. No: 1, Bilkent 06610, Ankara, Türkiye. e-mail: gulin_yegin@hotmail.com 
with $5 \mathrm{~cm}$ diameter was observed during surgery, and left salpingo-0ophorectomy was performed. The mass was placed in an endobag and subdivided into two parts. Then, 3-cm left lower-quadrant trocar incision was made. The intraoperative frozen sections were investigated, and the mass was reported as "fibroma." Right salpingo-oophorectomy was performed due to prophylaxis and all incisions, and the fascia and skin were sutured with 1/0 polyglactin 910 (Vicryl, Ethicon) and 2/0 polypropylene (Prolen, Ethicon), respectively. Since no complications were observed intra- and postoperatively, the patient was discharged 2 days after the surgery.

However, the patient was admitted to the emergency service with intermittent nausea, vomiting, and left abdominal pain 6 days after the surgery. The clinical examination did not reveal any significant findings (hyperpyrexia, abdominal distension, hyperemia, or swelling at the port site), and hematological and biochemical parameters were within the normal range. However, ultrasound and computed tomography (CT) imaging displayed left port-site hernia (Richter's hernia) (Figure 1).

The patient underwent laparotomy with the diagnosis of left port-site hernia (Richter's hernia). The previous left lowerquadrant trocar incision was repeated carefully. Care was taken, and the gut reposted back manually without causing damage. The reposted gut was examined and found to be viable. The incision was closed with 1/0 polydioxanone (PDS, Ethicon) suture. The patient recovered well after the procedure and was discharged 2 days later.

\section{DISCUSSION}

The incidence of trocar hernias ranges from $0.2 \%$ to $3.1 \%$ in large case series and reviews (3-7). The factors implicated in the pathogenesis of trocar site hernias are not clearly understood. Large trocar size, pyramidal trocars, entry and closure techniques, incomplete closure of fascia at the trocar site, midline trocars, stretching the port site for organ retrieval, effect of a partial vacuum during port withdrawal, preexisting fascial defects, obesity, older age, poor nutrition, and operation site infection are some of the common factors associated with the development of these hernias $(6,8,9,10,11)$.

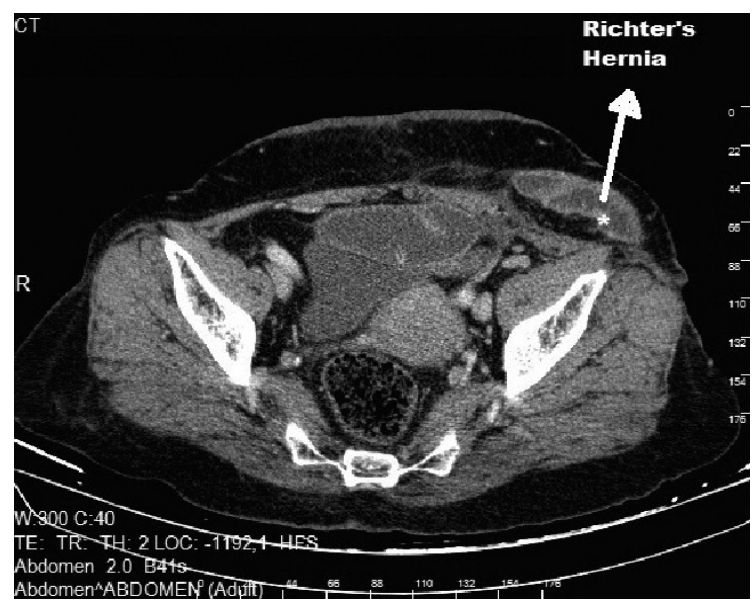

FIGURE 1: Left port-site hernia (Richter's hernia) on computed tomography.

Even if delayed hernias have been reported up to a year from the initial operation, most hernias present within 10 days from the procedures $(9,10)$. Tonouchi et al. have suggested a classification system depending on the time of presentation from the index operation (8). The early onset type occurs within 2 weeks postoperatively and most commonly with small bowel obstruction. On the contrary, the late onset type occurs after 2 weeks and had dehiscence of fascial plane with a sac consisting of peritoneum. The third category includes special types of ventral abdominal hernias $(9,10)$.

The clinical course of port-site hernia can be varied and depends on the extent and nature of the herniated content. It may also be asymptomatic or cause pain, fever, periumbilical mass, obvious evisceration, and mechanical bowel obstruction. However, nausea, vomiting, lack of appetite, and abdominal distension often can be seen postoperatively, or swelling and pain at the incision site may be hard to differentiate from a hematoma or wound infection. Since the clinical presentation of trocar site hernias is variable and may be hard to diagnose immediately, high suspicion is also required for correct diagnosis and prompt remediation $(7,8)$.

Richter's hernias contain only a portion of the intestine in the defect, and the diagnosis is often delayed because typical symptoms and findings of mechanical bowel obstruction may be absent (4). The initial symptom is usually pain. These hernias 
most often occur in incisions that are lateral to the midline where a high amount of preperitoneal fat is present creating a potential space for incarceration (6). This condition is difficult to diagnose and requires a high index of suspicion.

The management of laparoscopic incisional defects depends on the time of presentation and the presence of entrapped bowel. Evisceration always requires surgical intervention. If the condition is diagnosed immediately with no evidence of necrosis and intestinal defect, the intestine is replaced into the peritoneal cavity. If the diagnosis is delayed or the bowel is incarcerated or at risk of perforation, it is necessary to repair or resect the intestine.

In conclusion, it is necessary to repair the fascial and peritoneal layers to prevent port-site hernia. Prompt investigation and further intervention may reduce unfavorable events if a portsite hernia is suspected. Most port-site hernias present within 10 days of the primary procedures. A computed tomography scan is a helpful adjunct to diagnose port-site herniation. The knowledge of such a complication and its early diagnosis are important to avoid complications.

\section{REFERENCES}

1. Vecchio R, MacFayden BV, Palazzo F. history of laparoscopic surgery. Panminerva Med 2000;42(1):89-90.
2. Nieboer TE, Johnson N, Lethaby A, Tavender E, Curr E, Garry $R$, van Voorst S, Mol BW, Kluivers KB. Surgical approach to hysterectomy for benign gynaecological disease. Cochrane Database Syst Rev 2009;8(3):CD003677. doi: 10.1002/14651858.CD003677.pub4

3. Kadar N, Reich H, Liu CY, Manko GF, Gimpelson R. Incisional hernias after major laparoscopic gynecologic procedures. Am J Obstet Gynecol 1993;168(5):1493-5.

4. Nezhat C, Nezhat F, Seidman DS, Nezhat C. Incisional hernias after operative laparoscopy. J Laparoendosc Adv Surg Tech A 1997;7(2):111-5.

5. Azurin DJ, Go LS, Arroya LR, Kirkland ML. Trocar site herniation following laparoscopic cholecystectomy and the siginificance of an incidental preexisting umblical hernia. Am Surg 1995;61(8):718-20.

6. Montz FJ, Holschneider $\mathrm{CH}$, Munro MG. Incisional hernia following laparoscopy: a survey of the American Association of Gynecologic Laparoscopists. Obstet Gynecol 1994;84(5):881-4.

7. Lajer $\mathrm{H}$, Widecrantz $\mathrm{S}$, Heisterberg L. Hernias in trocar ports following abdominal laparoscopy. A review. Acta Obstet Gynecol Scand 1997;76(5):389-93.

8. Khurshid N, Chung M, Horrigan T, Manahan K, Geisler JP. 5-milimeter trocar-site bowel herniation following laparoscopic surgery. Khurshid N, Chung M, Horrigan T, Manahan K, Geisler JP JSLS. 2012;16(2):306-10.

9. Mayol J, Garcia-Aguilar J, Ortiz-Oshiro E, De-Diego Carmona JA, Fernandez-Represa JA. Risks of the minimal access approach for laparoscopic surgery: multivariate analysis of morbidity related to umbilical trocar insertion. World J Surg 1997;21(5):529-533.

10. Tonouchi H, Ohmori Y, Kobayashi M, Kusunoki M. Trocar site hernia. Arch Surg 2004;139(11):1248-12.

11. Lee JH, Kim W. Strangulated small bowel hernia through the port site: a case report. World J Gastroenterol 2008;14(44):6881-3. 